\title{
Mycoplasma indiense sp. nov., Isolated from the Throats of Nonhuman Primates
}

\author{
AURIOL C. HILL \\ Medical Research Council Toxicology Unit, Woodmansterne Road, Carshalton, \\ Surrey SM5 4EF, United Kingdom
}

\begin{abstract}
Mycoplasmas isolated from the throats of a rhesus monkey and a baboon within 3 days of their arrival from India were shown to be serologically distinct from 104 previously recognized Mycoplasma and Acholeplasma spp. Two mycoplasma colonies were cloned and examined in detail for morphology, growth, and biochemical characteristics. The two strains were closely related and had the following properties: guanine-plus-cytosine content of $32 \mathrm{~mol} \%$, requirement for sterol, arginine hydrolysis, and anaerobic growth. Glucose was not metabolized, and urea was not hydrolyzed. Strain 3T (= NCTC 11728) is the type strain of a new species, Mycoplasma indiense.
\end{abstract}

Several species in the class Mollicutes have been isolated from primates, and some of these species have been isolated from both human and nonhuman primates $(3,6,17,19,21$, 31). Most of the surveys on nonhuman primates were carried out with animals that had been housed for some time under laboratory conditions.

A survey was carried out to examine the mycoplasmal throat flora of various wild primates within 3 days of their arrival in the United Kingdom from India (15). The majority of the strains isolated were identified as Mycoplasma buccale and Mycoplasma salivarium, but a few were not identified. These isolates belonged to two groups; one group contained strains $21 \mathrm{E}$ and $26 \mathrm{D}$, and the other group contained strains $3 \mathrm{~T}^{\mathrm{T}}(\mathrm{T}=$ type strain) and $5 \mathrm{~T}$. The members of the first group exhibited one-way cross-reactions with $M y$ coplasma faucium, which is inhi"ited by antisera to strains $21 \mathrm{E}$ and 26D (16). Strains $21 \mathrm{E}$ and 26D appear to be closely related to each other and to strain 3539 isolated in Holland (24a). The members of the second group did not cross-react with $M$. faucium. Two additional strains, strain SPF recovered from a marmoset in a closed colony and strain HSPP isolated from a chimpanzee (6), are related to each other and also exhibit one-way cross reactions with $M$. faucium strains, but not with strains $21 \mathrm{E}$ and 26D (16).

In this paper I describe the characteristics of two isolates, strain $3 \mathrm{~T}^{\mathrm{T}}$, which was isolated from a rhesus monkey (Macaca mulatta), and strain 5T, which was isolated from a baboon (Papio anubis), and I demonstrate that these strains are distinct from all other mycoplasma species. My description of these strains is in accord with the standards published in $1979(32)$.

\section{MATERIALS AND METHODS}

Mycoplasma strains. Mycoplasmas were isolated in 1974 and $\mathbf{1 9 7 5}$ from the throats of a rhesus monkey and a baboon. A culture of each isolate was cloned to produce a pure culture by using a method involving initial filtration of a broth culture through a 220 -nm-pore-size membrane filter, culturing of the filtrate on solid medium, transfer of a single resulting colony to another agar plate, and inoculation of the subsequent growth into broth. This whole procedure was repeated four times; thus, the organisms were filter cloned five times (32). One of the clones (the clone isolated from the rhesus monkey) was designated strain $3 \mathrm{~T}^{\mathrm{T}}$, and the other clone (the clone isolated from the baboon) was designated strain 5T.

Mycoplasma species. Mycoplasma type strains were obtained from the National Collection of Type Cultures, Colindale, England, and from H. Atobe, M. F. Barile, J. M. Bradbury, R. J. Fallon, E. A. Freundt, J. T. Heywood, F. T. W. Jordan, D. E. Jaspar, H. Kirchoff, R. H. Leach, G. J. McGarrity, D. L. Rose, G. Smith, D. Taylor-Robinson, and J. G. Tully.

The following Mycoplasma spp. type strains were used: $M$. agalactiae PG2, $M$. alkalescens PG51, $M$. alvi Ilsley, $M$. anatis $1340, M$. anseris $1219, M$. arginini $\mathrm{G} 230, M$. arthritidis PG6, $M$. bovigenitalium PG11, $M$. bovirhinis PG43, $M$. bovis PG45, M. bovoculi M165/69, M. buccale CH-20247, $M$. californicum ST-6, $M$. canadense 275C, $M$. canis PG14, $M$. capricolum California kid, $M$. caviae $\mathrm{G} 122, M$. cavipharyngis $117 \mathrm{C}, M$. citelli $\mathrm{RG}-2 \mathrm{C}, M$. cloacale $383, M$. collis $58 \mathrm{~B}$, $M$. columbinasale $694, M$. columbinum MMP1, $M$. columborale MMP4, $M$. conjunctivae HRC581, $M$. cricetuli $\mathrm{CH}, M$. cynos $\mathrm{H} 831, M$. dispar 462/2, $M$. edwardii PG24, $M$. ellychniae ELCN-1, $M$. equigenitalium T37, $M$. equirhinis M432/ 72, $M$. fastidiosum 4822, $M$. faucium DC333, $M$. felifaucium PU, M. feliminutum Ben, $M$. felis CO, M. fermentans PG18, M. flocculare MS42, M. gallinaceum DO, M. gallinarum PG16, M. gallisepticum PG31, M. gallopavonis WR1, $M$. gateae CS, M. genitalium G-37, $M$. glycophilum 486, $M$. hominis $\mathrm{PG} 21, M$. hyopharyngis $\mathrm{H3}-6 \mathrm{BF}, M$. hyopneumoniae $\mathrm{J}, M$. hyorhinis $\mathrm{BT} 57, M$. hyosynoviae $\mathrm{S} 16, M$. iners PG30, $M$. iowae 695, M. lactucae 831-C4, M. leocaptivus 3L2, M. leopharyngis LL2, M. lipofaciens R171, M. lipophilum $\mathrm{MaBy}, M$. luminosum PIMN-1, M. lucivorax PIPN-2, M. maculosum PG15, M. melaleucae M1, $M$. meleagridis 17529, $M$. moatsii MK405, M. mobile $163 \mathrm{~K}, M$. molare H542, M. muris RIII4, M. mustelae MX9, M. mycoides subsp. capri PG3, M. mycoides subsp. mycoides PG1, $M$. neurolyticum Type A, $M$. opalescens MH5408, $M$. orale CH-19299, M. ovipneumoniae Y98, M. oxoniensis 128 , $M$. pirum HRC70-159, $M$. pneumoniae $\mathrm{FH}, M$. primatum HRC292, $M$. pullorum CKK, $M$. pulmonis PG34 (= ASH), $M$. putrefaciens KS-1, $M$. salivarium PG20, $M$. simbae LX, $M$. somnilux PYAN-1, $M$. spermatophilum AH159, $M$. spumans PG13, M. sualvi Mayfield (clone B), M. subdolum 
TB, $M$. synoviae WVU1853, $M$. testudinis 01008 , and $M$. verecundum 107.

The following Acholeplasma spp. type strains were used: $A$. axanthum $\mathrm{S} 743, A$. cavigenitalium GP3, $A$. entomophilum TAC, $A$. equifetale N93, $A$. flonum LI, $A$. granularum BTS39, $A$. hippikon $\mathrm{CI}, A$. laidlawii $\mathrm{PG} 8, A$. modicum PG49, $A$. morum 72-043, A. multilocale PN525, A. oculi 19L, and $A$. parvum $\mathrm{H} 23 \mathrm{M}$.

Medium and growth conditions. The culture medium used has been described previously $(13,34)$ and contained thallium acetate and penicillin. The purified agar used in the growth medium was either Ionagar No. 2 (Oxoid Ltd., Basingstoke, England) or Lab M agar (Lab M, London, England). Depending on their biochemical activities, the mycoplasmas were grown in liquid medium containing $1 \%$ (wt/vol) glucose ( $\mathrm{pH} 7.8$ ) or in liquid medium containing 0.5 to $1 \%(w t / v o l)$ arginine $(\mathrm{pH} \mathrm{7.3)}$. The species grown in medium containing arginine were not inhibited by $1 \%$ arginine. Agar cultures were incubated at 35 to $37^{\circ} \mathrm{C}$ either in a humid chamber or under anaerobic conditions in a GasPak system. Liquid cultures were stored at $-70^{\circ} \mathrm{C}$ in ampoules.

Growth requirements and characteristics. The clones were subcultured onto solid medium and incubated for 1 week under both aerobic and GasPak anaerobic conditions at 35 to $37^{\circ} \mathrm{C}$. The levels of susceptibility to methylene blue were determined by adding $0.002 \%$ (wt/vol) methylene blue to the basal solid medium and comparing the growth of inoculated mycoplasmas with the growth of mycoplasmas cultivated on medium without methylene blue. Lipolytic activity was tested by inoculating mycoplasmas onto basal medium enriched with $10 \%$ egg yolk emulsion (9). The incubated plates were examined at 3,7 , and 14 days for visual evidence of lipolysis (clearing) or film production (film and spots).

Absence of reversion. The clones were subcultured by five passages in both solid and liquid media that contained no microbial inhibitors in order to determine whether the organisms reverted to bacterial forms. Agar culture colonies of each clone were also treated with Dienes stain in order to differentiate mycoplasma colonies from bacterial L-forms (35).

Morphological studies. Mycoplasma colonies grown on agar were examined microscopically at a magnification of $\times 100$ after 3,7 , and 14 days of incubation. The colonies were transferred to slides and stained with Giemsa stain $(10,18)$. Liquid cultures were observed by using dark-field microscopy, and organisms were stained with Giemsa stain (18). Organisms grown in broth were harvested by centrifugation, and the resulting cell pellets were fixed in $2 \%$ ( $\mathrm{vol} / \mathrm{vol})$ glutaraldehyde and postfixed in $1 \%$ (wt/vol) osmium tetroxide for $1 \mathrm{~h}$. Thin sections of these preparations were stained with uranyl acetate and lead citrate and examined by electron microscopy (38).

Filtration studies. Cultures (after $24 \mathrm{~h}$ of incubation) were diluted 1:10 in liquid medium, and the resulting preparations were filtered and refiltered (with a syringe and slight pressure) through a series of membrane filters (Millipore Corp., Bedford, Mass.) with pore diameters of 220, 300, 450, 650, and $800 \mathrm{~nm}$. The number of colony-forming units per milliliter in each filtrate was determined by plating the filtrate onto agar and was compared with the number of colonyforming units per milliliter in the unfiltered culture dilution.

Sterol dependence. Single colonies of strains $3 \mathrm{~T}^{\mathrm{T}}$ and $5 \mathrm{~T}$ were seeded onto serum-free solid media supplemented with $0.5 \%$ bovine serum albumin, $0.5 \%$ glucose, and $10 \mu \mathrm{g}$ of palmitic acid per ml. Cholesterol dissolved in Tween 80 was added to give final cholesterol concentrations of $20,10,5$, and $1 \mu \mathrm{g} / \mathrm{ml}$. Plates containing no cholesterol were included $(7,8,28,37)$. The mycoplasmas were also subcultured onto the basal agar medium without serum. When growth occurred on any of the serum-free media, single colonies were passaged three times on the same medium to ensure that growth was not due to a carryover of serum from the original culture, which would have given misleading results.

The clones were also tested indirectly for sterol dependence by a paper disk inhibition method (11), using either dried disks that originally contained $0.02 \mathrm{ml}$ of a $1.5 \%$ (wt/vol) ethanolic solution of digitonin (Sigma Chemical Co., St. Louis, Mo.) or wet disks that contained $0.02 \mathrm{ml}$ of a $20 \%$ (wt/vol) aqueous solution of sodium polyanethol sulfonate (Koch-Light Laboratories, Ltd., Colnbrook, England) on basal growth medium containing Lab $\mathrm{M}$ agar. The widths (in millimeters) of zones of growth inhibition were measured.

Biochemical activity. The clones were examined for metabolism of arabinose, arbutin, cellobiose, dulcitol, fructose, galactose, glucose, glycerol, inositol, lactose, maltose, mannitol, mannose, raffinose, rhamnose, salicin, sorbitol, sucrose, trehelose, and xylose; for hydrolysis of esculin, arginine ( 1 and $0.1 \%$ ), and urea; for reduction of methylene blue, resazurin, tetrazolium, and tellurite; and for phosphatase activity $(1,2,20,30,36,39)$. Positive and negative controls were used for all of the tests except some of the carbohydrate tests. All of the preparations which yielded negative results were checked for viability of the organism.

Erythrocyte techniques. The clones were examined for hemolytic activity, hemadsorption, and hemagglutination with guinea pig, human, and sheep erythrocytes $(1,22)$.

Polyacrylamide gel electrophoresis. Electrophoresis was carried out as described by Mouches and Bové (24), using a one-dimensional slab. Centrifuged cell suspensions were dissolved in a solution containing $20 \%$ glycerol, 5\% 2-mercaptoethanol, and 3\% sodium dodecyl sulfate in $0.00625 \mathrm{M}$ Tris buffer ( $\mathrm{pH} 6.8$ ). To a $12.5 \%$ acrylamide gel 10 - or $25-\mu 1$ portions of a cell sample were added. Electrophoresis was performed at room temperature for $1 \mathrm{~h}$ at a constant current (20 mA). The gels were stained with Coomassie blue (Sigma).

DNA base composition. DNA was extracted from centrifuged broth culture deposits of strain $3 \mathrm{~T}^{\mathrm{T}}$ by using the method of Gross-Bellard et al. (12), and the guanine-pluscytosine content was determined from the buoyant density

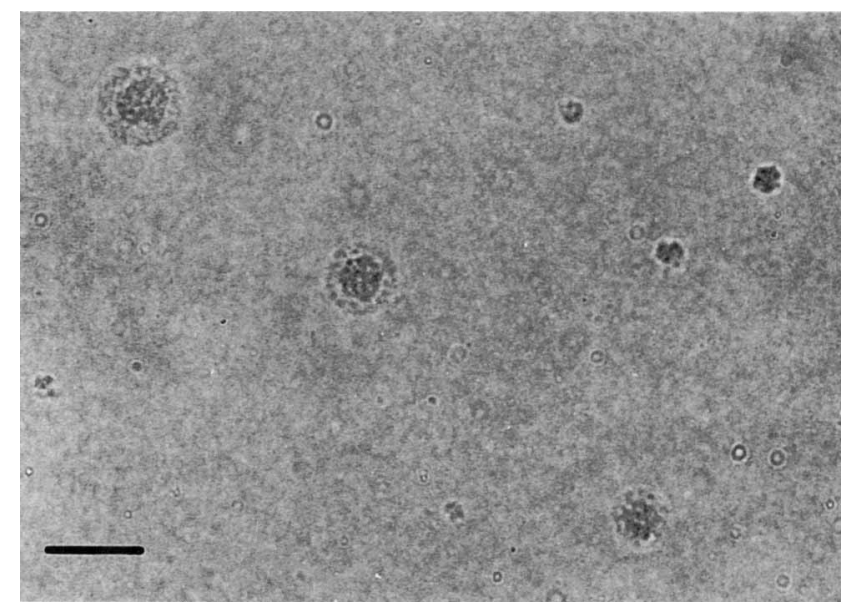

FIG. 1. Colonies of strain $3 \mathrm{~T}^{\mathrm{T}}$ grown under anaerobic conditions for 3 days on an agar medium. Bar $=50 \mu \mathrm{m}$. 
of the DNA in cesium chloride by ultracentrifugation (29). DNA extracted from Escherichia coli, which had a known guanine-plus-cytosine content, was included as a control.

Serological studies. Antisera were prepared as described by Morton and Roberts (23) and Hill (13). The following three serological methods were used: growth inhibition tests with antiserum-impregnated sterile paper disks (5), metabolism inhibition tests in microtiter plates $(14,26,27,33)$, and immunoperoxidase tests with colonies grown on agar (25). All of the tests were carried out in duplicate. Strains $3 \mathrm{~T}^{\mathrm{T}}$ and $5 \mathrm{~T}$ were reacted with antisera prepared against the species listed above. Antisera to the two strains were tested with the previously described Mycoplasma and Acholeplasma species. Antisera to the two strains were also reacted with each other to demonstrate their relationship.

\section{RESULTS AND DISCUSSION}

Colonies of strains $3 \mathrm{~T}^{\mathrm{T}}$ and $5 \mathrm{~T}$ became visible during primary isolation after 7 to 8 days of incubation under anaerobic conditions, but growth was more rapid after several passages and became visible after 3 days. No growth was visible aerobically even after prolonged incubation or after many passages on the mycoplasma culture medium. The colonies (Fig. 1) had a typical fried egg appearance. No growth was observed on methylene blue agar or on medium without serum. A film was produced on egg yolk agar, and the clones showed lipolytic activity. Neither clone reverted to a bacterial form when it was subcultured on medium without bacterial inhibitors. The colonies rapidly stained with Dienes reagent, suggesting that these isolates were true mycoplasmas (Mollicutes) rather than bacterial L-forms (35).

No motility was observed when the strains were examined by using dark-field microscopy, and helical forms were not seen. Liquid cultures stained with Giemsa stain contained pleomorphic forms characteristic of mycoplasmas. The ultrastructure of the organisms was typical of mycoplasma morphology when thin sections were viewed by electron microscopy (4). The cells were bounded by a single trilaminar unit membrane and lacked any evidence of a cell wall (Fig. 2).

Filtration of a broth culture of strain $3 \mathrm{~T}^{\mathrm{T}}$ reduced the viable count from $6 \times 10^{6} \mathrm{CFU} / \mathrm{ml}$ in the original dilution to $8 \times 10^{5} \mathrm{CFU} / \mathrm{ml}$ in the 300 -nm-pore-size membrane filtrate and $2 \times 10^{4} \mathrm{CFU} / \mathrm{ml}$ in the 220 -nm-pore-size membrane filtrate.

Strains $3 \mathrm{~T}^{\mathrm{T}}$ and $5 \mathrm{~T}$ could not be cultured on medium without cholesterol, but they grew and were passaged on medium containing $5 \mu \mathrm{g}$ of cholesterol per $\mathrm{ml}$. They were susceptible to digitonin and sodium polyanethol sulfonate

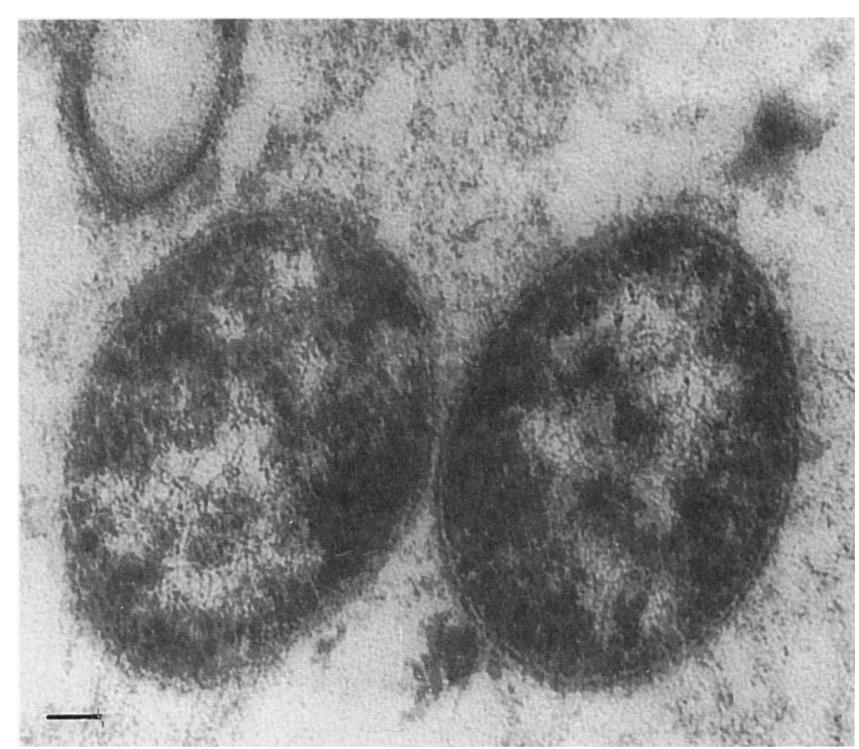

FIG. 2. Electron micrograph of a section of strain $3 \mathrm{~T}^{\mathrm{T}}$ stained with uranyl acetate and lead citrate. Bar $=100 \mathrm{~nm}$.

(zones of growth inhibition, 8 and $10 \mathrm{~mm}$, respectively); under these conditions growth was semiconfluent.

The biochemical activities of the two strains were identical and are summarized in the species description below. Only arginine was hydrolyzed. In appropriate tests both strains were hemolytic for guinea pig, human, and sheep erythrocytes but did not hemadsorb or hemagglutinate these cells.

The two strains produced similar electrophoretic protein patterns, and these patterns were distinct from the patterns produced by other arginine-hydrolyzing primate mycoplasmas.

The guanine-plus-cytosine content of strain $3 \mathrm{~T}^{\mathrm{T}}$ was determined from its buoyant density in cesium chloride to be 32 mol\%. This value is within the range of values obtained for the previously characterized Mycoplasma species.

The serological techniques used revealed similar levels of cross-reactivity between the two strains (Table 1). No significant cross-reactions were detected with any of the species listed in Materials and Methods.

Taxonomic assignment. Strains $3 \mathrm{~T}^{\mathrm{T}}$ and $5 \mathrm{~T}$ belong to the family Mycoplasmataceae on the basis of their main properties, including absence of cell walls, lack of reversion to bacterial L-forms when the organisms are grown in antibiotic-free media, penicillin resistance, filterability, and production of typical morphology on agar. They belong to the genus

TABLE 1. Serological reactions of Mycoplasma spp. and strains $3 \mathrm{~T}^{\mathrm{T}}$ and $5 \mathrm{~T}$ with antisera to strain $3 \mathrm{~T}^{\mathrm{T}}$ and $M$. faucium

\begin{tabular}{|c|c|c|c|c|c|c|}
\hline \multirow{2}{*}{ Antigen } & \multicolumn{2}{|c|}{$\begin{array}{l}\text { Results of growth inhibition test } \\
\text { (mm) with antiserum to: }\end{array}$} & \multicolumn{2}{|c|}{$\begin{array}{l}\text { Titer in metabolic inhibition test } \\
\text { with antiserum to }{ }^{a} \text { : }\end{array}$} & \multicolumn{2}{|c|}{$\begin{array}{l}\text { Titer in immunoperoxidase test } \\
\text { with antiserum to }{ }^{b} \text { : }\end{array}$} \\
\hline & Strain $3 T^{\mathrm{T}}$ & M. faucium & Strain $3 \mathrm{~T}^{\mathrm{T}}$ & M. faucium & Strain $3 T^{\mathbf{T}}$ & M. faucium \\
\hline Strain $3 \mathrm{~T}^{\mathrm{T}}$ & 6 & 0 & 4,096 & $<32$ & 16,000 & $<100$ \\
\hline Strain 5T & 5 & 0 & 4,096 & $<32$ & 8,000 & $<100$ \\
\hline M. faucium & 0 & $3-4$ & $<32$ & 4,096 & $<100$ & 4,000 \\
\hline All other species ${ }^{c}$ & 0 & $\mathrm{NT}^{d}$ & $<32-64$ & NT & $<100$ & NT \\
\hline
\end{tabular}

\footnotetext{
${ }^{a}$ In the metabolism inhibition test the antiserum was diluted $1 / 16$ to $1 / 32,000$.

$b$ In the immunoperoxidase test the antiserum was diluted $1 / 100$ to $1 / 16,000$.

c Species listed in Materials and Methods.

${ }^{d}$ NT, not tested.
} 
Mycoplasma because they are not strict anaerobes (in contrast to Anaeroplasma spp.), are nonhelical (in contrast to Spiroplasma spp.), and depend on sterol for growth (in contrast to Acholeplasma spp.) and because urease activity could not be demonstrated (in contrast to Ureaplasma spp.).

Strains $3 \mathrm{~T}^{\mathrm{T}}$ and $5 \mathrm{~T}$ belong to the same species because they have identical biological characteristics and produce identical serological and protein patterns. As there were no significant cross-reactions with any of the previously recognized Mycoplasma spp. (see above), strains $3 \mathrm{~T}^{\mathrm{T}}$ and $5 \mathrm{~T}$ belong to a new species. The name Mycoplasma indiensis sp. nov. is proposed for these organisms.

Description of Mycoplasma indiense sp. nov. Mycoplasma indiense (in.di.en'se. N. L. gen. indiense, pertaining to India, where the infected primates originated).

Morphological and physical characteristics. Pleomorphic cells bounded by a single unit membrane. Colonies on agar have a typical fried egg appearance. Organisms are filterable through 220 -nm-pore-size membrane filters and are resistant to penicillin.

Growth characteristics. Requires sterol, but is inhibited by digitonin and sodium polyanethol sulfonate. Optimal growth occurs at 35 to $37^{\circ} \mathrm{C}$ under anaerobic conditions. Produces a film and exhibits lipolytic activity on agar.

Metabolic characteristics. Glucose is not metabolized; arginine (but not urea) is hydrolyzed.

Serological characteristics. Serologically distinct from all previously described Mycoplasma species.

DNA base composition. The DNA base composition is 32 mol\% guanine-plus-cytosine.

Habitat. The habitat is nonhuman primate throats.

Type strain. The type strain is strain 3T (= NCTC 11728).

\section{ACKNOWLEDGMENTS}

I thank C. Colhoun and I. Whisson for supplying the photographs.

\section{REFERENCES}

1. Aluotto, B. B., R. G. Wittler, C. O. Williams, and J. E. Faber. 1970. Standardized bacteriologic techniques for the characterization of Mycoplasma species. Int. J. Syst. Bacteriol. 20:3558.

2. Barber, T. L., and J. Fabricant. 1971. Identification of Mycoplasmatales: characterization procedures. App. Microbiol. 21: 600-605.

3. Barile, M. F. 1973. Mycoplasmal flora of simians. J. Infect. Dis. 127:S17-S20.

4. Boatman, E. S. 1979. Morphology and ultrastructure of the Mycoplasmatales, p. 63-102. In M. F. Barile and S. Razin (ed.), The mycoplasmas, vol. 1. Academic Press, Inc., New York.

5. Clyde, W. A., Jr. 1964. Mycoplasma species identification based upon growth inhibition by specific antisera. J. Immunol. 92:958-965.

6. Cole, B. C., J. R. Ward, L. Golightly-Rowland, and C. E. Graham. 1970. Characterization of mycoplasmas isolated from the great apes. Can. J. Microbiol. 16:1331-1339.

7. Edward, D. G. ff. 1971. Determination of sterol requirement for Mycoplasmatales. J. Gen. Microbiol. 69:205-210.

8. Edward, D. G. ff., and W. A. Fitzgerald. 1951. Cholesterol in the growth of organisms of the pleuropneumonia group. J. Gen. Microbiol. 5:576-586.

9. Fabricant, J., and E. A. Freundt. 1967. Importance of extension and standardization of laboratory tests for the identification and classification of mycoplasma. Ann. N.Y. Acad. Sci. 143:50-58.

10. Fallon, R. J., and P. Whittlestone. 1969. Isolation, cultivation and maintenance of mycoplasmas. Methods Microbiol. 3B:211267.
11. Freundt, E. A., B. E. Andrews, H. Erno, M. Kunze, and F. T. Black. 1973. The sensitivity of Mycoplasmatales to sodiumpolyanethol sulfonate and digitonin. Zentralbl. Bakteriol. Parasitenkd. Infektionskr. Hyg. Abt. 1 Orig. Reihe A 225:104 112.

12. Gross-Bellard, M. J., P. Oudet, and P. Chambon. 1973. Isolation of high molecular weight DNA from mammalian cells. Eur. J. Biochem. 36:32-38.

13. Hill, A. C. 1971. Mycoplasma caviae, a new species. J. Gen. Microbiol. 65:109-113.

14. Hill, A. C. 1977. The metabolic inhibition test for mycoplasmas based on phosphatase production. J. Hyg. 79:391-393.

15. Hill, A. C. 1977. The isolation of mycoplasmas from non-human primates. Vet. Rec. 101:117.

16. Hill, A. C. Unpublished data.

17. Hutchison, V. E., M. E. Pinkerton, and S. S. Kalter. 1970. Incidence of mycoplasma in nonhuman primates. Lab. Anim. Care 20:914-922.

18. Klieneberger-Nobel, E. 1962. Morphology of pleuropneumonialike organisms, p. 23-56. In E. Klieneberger-Nobel (ed.), Pleuropneumonia-like organisms (PPLO). Mycoplasmataceae. Academic Press, Inc., New York.

19. Koshimizu, K., T. Magaribuchi, K. Yamamoto, and M. Ogata. 1975. Characterization of mycoplasmas isolated from imported nonhuman primates. Exp. Anim. 24:95-101.

20. Leach, R. H. 1976. The inhibitory effect of arginine on growth of some mycoplasmas. J. Appl. Bacteriol. 41:259-264.

21. Madden, D. L., R. J. Hildebrandt, G. R. G. Monif, W. T. London, J. L. Sever, and N. B. McCullough. 1970. The isolation and identification of mycoplasma from Macaca mulatta. Lab. Anim. Care 20:467-470.

22. Manchee, R. J., and D. Taylor-Robinson. 1968. Haemadsorption and haemagglutination by mycoplasmas. J. Gen. Microbiol. 50:465-478.

23. Morton, H. E., and R. J. Roberts. 1967. Production of antimycoplasma (PPLO) antibodies in rabbits. Proc. Soc. Exp. Biol. Med. 125:538-543.

24. Mouches, C., and J. M. Bové. 1983. Electrophoretic characterization of mycoplasma proteins. Methods Mycoplasmol. 1:241255.

24a.Polak-Vogelzang, A. Personal communication.

25. Polak-Vogelzang, A. A., R. Hagenaars, and S. Nagel. 1978. Evaluation of an indirect immunoperoxidase test for identification of Acholeplasma and Mycoplasma. J. Gen. Microbiol. 106:241-249.

26. Purcell, R. H., D. Taylor-Robinson, D. C. Wong, and R. M. Chanock. 1966. A color test for the measurement of antibody to the non-acid-forming human mycoplasma species. Am. J. Epidemiol. 84:51-66.

27. Purcell, R. H., D. Taylor-Robinson, D. Wong, and R. M. Chanock. 1966. Color test for the measurement of antibody to T-strain mycoplasmas. J. Bacteriol. 92:6-12.

28. Razin, S., and J. G. Tully. 1970. Cholesterol requirement of mycoplasmas. J. Bacteriol. 102:306-310.

29. Schildkraut, C. L., J. Marmur, and P. Doty. 1962. Determination of the base composition of deoxyribonucleic acid from its buoyant density in CsCl. J. Mol. Biol. 4:430-443.

30. Shepard, M. C., and D. R. Howard. 1970. Identification of " $T$ " mycoplasmas in primary agar cultures by means of a direct test for urease. Ann. N.Y. Acad. Sci. 174:809-819.

31. Somerson, N. L., and B. C. Cole. 1979. The mycoplasma flora of human and non-human primates, p. 191-216. In J. G. Tully and R. F. Whitcomb (ed.), The mycoplasmas, vol. 2. Academic Press, Inc., New York.

32. Subcommittee on the Taxonomy of Mollicutes. 1979. Proposal of minimal standards for descriptions of new species of the class Mollicutes. Int. J. Syst. Bacteriol. 29:172-180.

33. Taylor-Robinson, D., R. H. Purcell, D. C. Wong, and R. M. Chanock. 1966. A colour test for the measurement of antibody to certain mycoplasma species based upon the inhibition of acid production. J. Hyg. 64:91-104.

34. Taylor-Robinson, D., M. H. Williams, and D. A. Haig. 1968. The isolation and comparative biological and physical characteris- 
tics of T-mycoplasmas of cattle. J. Gen. Microbiol. 54:33-46.

35. Timms, L. 1967. Isolation and identification of avian mycoplasmas. J. Med. Lab. Technol. 24:79-89.

36. Tully, J. G. 1965. Biochemical, morphological and serological characterization of mycoplasma of murine origin. J. Infect. Dis. 115:171-185.

37. Tully, J. G., and S. Razin. 1969. Characteristics of a new sterol-non-requiring mycoplasma. J. Bacteriol. 98:970-978.

38. Venable, J. H., and R. Coggeshall. 1965. A simplified lead citrate stain for use in electron microscopy. J. Cell Biol. 25:407.

39. Williams, C. O., and R. G. Wittler. 1971. Hydrolysis of esculin and phosphatase production by members of the order $\mathrm{Myco}$ plasmatales which do not require sterol. Int. J. Syst. Bacteriol. 21:73-77. 